\title{
Minimal Distension or Minimal Duration of Pharyngoesophageal Segment Opening During Swallowing
}

National Cancer Institute

\section{Source}

National Cancer Institute. Minimal Distension or Minimal Duration of

Pharyngoesophageal Segment Opening During Swallowing. NCI Thesaurus. Code

C127322.

A finding of minimal distension or minimal duration of pharyng oesophageal segment opening during swallowing; marked obstruction of flow. 